\title{
New methods to measure the built environment for human-scale travel research: Individual access corridor (IAC) analytics to better understand sustainable active travel choices
}

\author{
Bruce Appleyard \\ San Diego State University \\ bappleyard@mail.sdsu.edu
}

\begin{abstract}
While travel is an inherently linear activity, most studies rely on coarse zonal measures of the built environment, likely missing key details important to human-scale travelers (pedestrians and bicyclists). To more fully understand these relationships, this study tests a new, linear spatial unit of analysis (the individual access corridor) in combination with finer-grained geospatial data (parcel, point, street network)—in sum, human-scaled measures for human-scale travel research.

This paper first analyzes the current state of practice, details the development of a set of new linear human-scaled measures, and finally, provides both a quantitative and qualitative assessment of their usefulness toward research and policy application.

This paper confirms that these new measures both improve model performance and, perhaps more importantly, provide richer, more nuanced insight into the influence of the built environment on humanscale travel. For example, this study finds that smaller parcels, the presence of small personal-service retail opportunities, and narrower, well-connected streets are positively associated with walking and bicycling.

Furthermore, this paper is one of the first to align built environment measures along an individual's path, from origin to destination, as well as to provide a detailed examination of the choice of bicycle over other modes.
\end{abstract}

\author{
Article history: \\ Received: October 6, 2014 \\ Accepted: December 15, 2014 \\ Available online: August 21, 2015
}

\section{Introduction}

Travel is an inherently linear activity. However, most travel behavior and built environment studies rely on coarsely aggregated zonal averages homogeneously attributed to unique individuals, thus likely missing key details important to individuals traveling outside protective vehicle confines: pedestrians and bicyclists. Furthermore, most studies focus on characteristics of the origin, omitting consideration of the destination (such as parking availability, price, etc.), let alone the quality of the environment in between (Boarnet 2011; Appleyard 2011; 2012). Further exacerbating the problem, most studies rely

Copyright 2015 Bruce Appleyard

http://dx.doi.org/10.5198/jtlu.2016.786

ISSN: 1938-7849 | Licensed under the Creative Commons Attribution - Noncommercial License 3.0

The Journal of Transport and Land Use is the official journal of the World Society for Transport and Land Use (WSTLUR) and is published and sponsored by the University of Minnesota Center for Transportation Studies. This paper is also published with sponsorship from WSTLUR and the Institutes of Transportation Studies at the University of California, Davis, and the University of California, Berkeley. 
on context insensitive, super-humanly scaled zones — census tracts, traffic analysis zones (TAZs), etc.which in turn limits the analysis and findings of these studies on what lowers auto use (vehicle miles traveled or VT) rather than what may actually encourage walking and/or bicycling (Appleyard 2011; 2012).

In response, this paper presents both an exploratory and confirmatory analysis of new geospatial (GIS) methods to measure the built environment for travel behavior research through the use of a new, linear spatial unit of analysis, the individual access corridor, in combination with more detailed, humanscale, "disaggregated" (geo-located point/parcel) data. In sum, this research tests whether the use of human-scale data for human-scale travel analyses improves our capacity to 1) properly assess the current strengths and weaknesses of the built environment for walking and bicycling, and 2) guide policy and design decisions to better serve all modes.

To ground the exploration and testing of these new measures, this paper applies their development to an examination of the influence of the built environment on travel behavior in a real-world situation-a multinomial logit (MNL) predictive mode choice analysis of a relatively standard travel survey: the 2008 Bay Area Rapid Transit (BART) Station Profile Survey. Next, to confirm that these new, linear measures of the built environment are indeed an improvement over conventional, zonally aggregated measures now commonly used in practice, statistically rigorous predictive MNL model comparison methods are used.

Building on Appleyard (2011), this work is guided by a central evaluative framework composed of four core principles: resolution, respondent, replicability, and (policy) relevance-referred herein as the " $4 \mathrm{R}$ principles of methodological development." In sum, through the use of relevant, high-resolution data uniquely attributed to each individual survey respondent (along their linear path of travel) in a replicable, objective manner for a large enough group of people to support statistical significant analyses of the built environment's influence on travel behavior, we are better equipped to guide policy and design decisions.

This study shows that by aligning more detailed, human-scale measures along an individual's path of travel, we are able to improve our understanding of the choice of "green and active modes" (walking and bicycling) — central to our achieving important environmental and health benefits for our society.

\subsection{Brief review of the state of the practice}

\subsubsection{Complexity of the relationship between the built environment and travel behavior}

Early interest in the influence of land use on travel behavior focused on the connection between residential densities and transit use (Pushkarev and Zupan 1977), suggesting transit use can be increased through densification. Ever since, this research has proven itself to be complex and in constant need of refinement (Badoe and Miller 2000) . For example, Boarnet and Sarmiento (1996) and Crane and Crepeau (1998) find weaker effects of urban form on travel, and Downs (2005) concludes that even with an extensive rail system, the clustering of housing near stations produces only a small reduction in traffic congestion. Alternatively, Cervero and Duncan (2003) find consistent positive relations between walking for transportation through the use of factor analysis to represent the urban design and landuse diversity dimensions of the built environment, and Saelens and Handy (2008) find similar, positive associations between walking, density, distance to non-residential destinations, and land-use mix. Nevertheless, numerous studies do show a degree of how travel is a derived demand driven by land use and urban design patterns (Badoe and Miller 2000; Boarnet and Crane 2001; Brownstone 2008; Crane 2000; Ewing \& Cervero, 2001, 2010; Handy 2005).

Two seminal meta-analyses of the body of this research by Ewing and Cervero $(2001 ; 2010)$ find that many aspects of the built environment have a significant, although sometimes limited, association 
with travel behavior. However, several caveats should be considered for this paper. First, other factors also are known to be statistically relevant to active travel behavior such as safety, security, topography, etc. (Lee and Moudon 2006; Moudon and Lee 2003). Finally, researchers have become concerned about residential self-selection biases (Cao, Mokhtarian, and Handy 2009; Cervero and Duncan 2002; Salon et al. 2012). Nevertheless, Cao et al. (2009) find that after correcting for residential selection, the built environment's effects were moderated but remained a significant factor.

\subsubsection{The rise of the $D$ variables: Limitations of conventional zonal aggregations analysis}

Since the mid-1990s, built environment variables have traditionally been defined as the " $\mathrm{D}$ variables" after language first used by Cervero and Kockelman (1997). The original "three Ds" were density, diversity, and design. The two seminal meta-analyses by Ewing and Cervero $(2001 ; 2010)$ added destination accessibility and distance to transit as fourth and fifth $\mathrm{D}$ variables. In most cases, this paper will refer to these in the following manner: density variable, diversity variable, etc.

As in 2001, Ewing and Cervero's 2010 meta-analyses were limited to studies with enough observations for statistical significance. Some studies (and constituent data) were excluded because variables were not "measured in a standardized way by researchers" (Ewing \& Cervero 2010)—that is, by objective, replicable methods. Furthermore, of almost all of the 200 studies reviewed in 2010, practically all data were aggregated to zonal levels — oftentimes at either 1/2-mile circles, census tracts, or traffic analysis zones (TAZs) — thus homogenously applying zonal averages (undermining the resolution principle) to unique individuals within these zonal units (undermining the respondent principle). Likely because of these constraints, most research reviewed in these two meta-analyses was limited to dealing with factors that lower auto use, rather than what might increase walking and/or bicycling.

This can be considered a modifiable areal unit problem (MAUP) - a methodological concern where, In the context of this work, the sensitivity of the association between the built environment and travel behavior is affected by the spatial scale at which built environment data are collected and amassed (Zhang and Kukadia 2005).

\section{Limited understanding of the built environment's influence on walking and bicycling}

In their 2001 synthesis, Ewing and Cervero (2001) focused only on auto-use outcome measures (VMT, auto-ownership, etc.) and did not include research directly addressing walking, transit use, or bicycling. In their 2010 meta-analysis, walking trips were found to have limited associations with diversity measures of land-use activity mixture and design variables of intersection density. And while this latter measure is commonly used in walkability-related measurement and modeling (Ewing et al. 2011), zonal measures of intersection density are arguably out of scale of the human travel experience. Furthermore, bicyclists were absent from both the 2001 and 2010 Ewing and Cervero meta-analyses. It is perhaps worth noting at this point that bicyclists appear to place relatively high value on such facilities as offstreet bike paths — enhanced neighborhood bikeways with traffic calming features (e.g., "bicycle boulevards")(Broach, Dill, and Gliebe 2012).

To provide guidance, Handy (2006) summarizes the state of built environment and physical activity (walking and bicycling for all trip purposes) research by saying the relationships "are perhaps not as strong or consistent as many readers would expect" because either 1) "the relationships really aren't strong or consistent;" or, as she then posits, "we haven't been studying them in the right way" (p. 43). Building on Badoe and Miller's (2000) review of empirical studies of transportation-land use interactions, and suggesting that the gaps in our understanding are "primarily the result of data limitations and methodological weaknesses" (Badoe and Miller 2000), this research gives greater salience to Handy's 
latter point and seeks to more closely align detailed urban form measures to the scale at which a person interacts with their environment-in other words, human-scale data for human-scale travel research.

\subsubsection{Refining current measures of the built environment for linear units of analysis}

Through the use of a linear individual access corridor, along with more finely detailed data now (e.g., point/parcel land use, employment, and travel survey responses), there are clear avenues to refine conventional travel behavior and built environment research practices. This section discusses limitations of current methods through an examination of several key D variables and their ability to 1) thoroughly diagnose the characteristics of the built environment as they relate to travel, and 2) relevantly guide decisions on policy and design that may improve the propensity for walking and bicycling.

\section{Zonal diversity variable}

At its core, the diversity variable is a measure of land-use activity. Conventionally, measuring diversity has been limited to zonal level dissimilarity of "entropy" indices as proxy measures of land-use mixture. As shown in the following example, these can belie key information about activity characteristics necessary to guide policy. Consider the application of this relatively standard formula Zhang et al. 2012; Cervero and Duncan 2003) for calculating a zonal (1/2-mile radius around a station) jobs-to-housing, mixed-use entropy index:

Jobs-to-housing/mixed-use entropy $\left.=\left\{-\Sigma / \mathrm{k}\left[\left(\mathrm{p}_{\mathrm{i}}\right)\left(\ln \mathrm{p}_{\mathrm{i}}\right)\right]\right\} /(\ln \mathrm{k})\right\}$

where:

$\mathrm{p}_{\mathrm{i}}=$ proportion of total land-use activities in category $\mathrm{i}$ within a half mile (straight-line distance) of the station;

i categories are households (\# of single family units; and \# of multifamily units), and employment (retail and non-retail jobs); and

$\mathrm{k}=4$ (number of land-use categories).

Station areas with heterogeneous mixes of housing and jobs scored high on these factors (based on the 0-1 entropy index, where 1 represents maximum heterogeneity).

One of the confounding factors of this type of entropy measure is its simultaneous capture of the mix between housing and jobs. One solution to avoid these confounding findings is to look separately at the mixture of commercial uses, independent of residential uses. The EPA's Smart Location Database (US EPA 2014), for example, includes such an entropy measure, which looks solely at the mixture of commercial uses. Another potentially useful measure of local land-use mix could be something similar to components of the Walkscore measure (Walkscore 2014), which provides a one-way, one-to-many relationship between a household and other important activities (retail, entertainment, employment opportunities, etc.). 


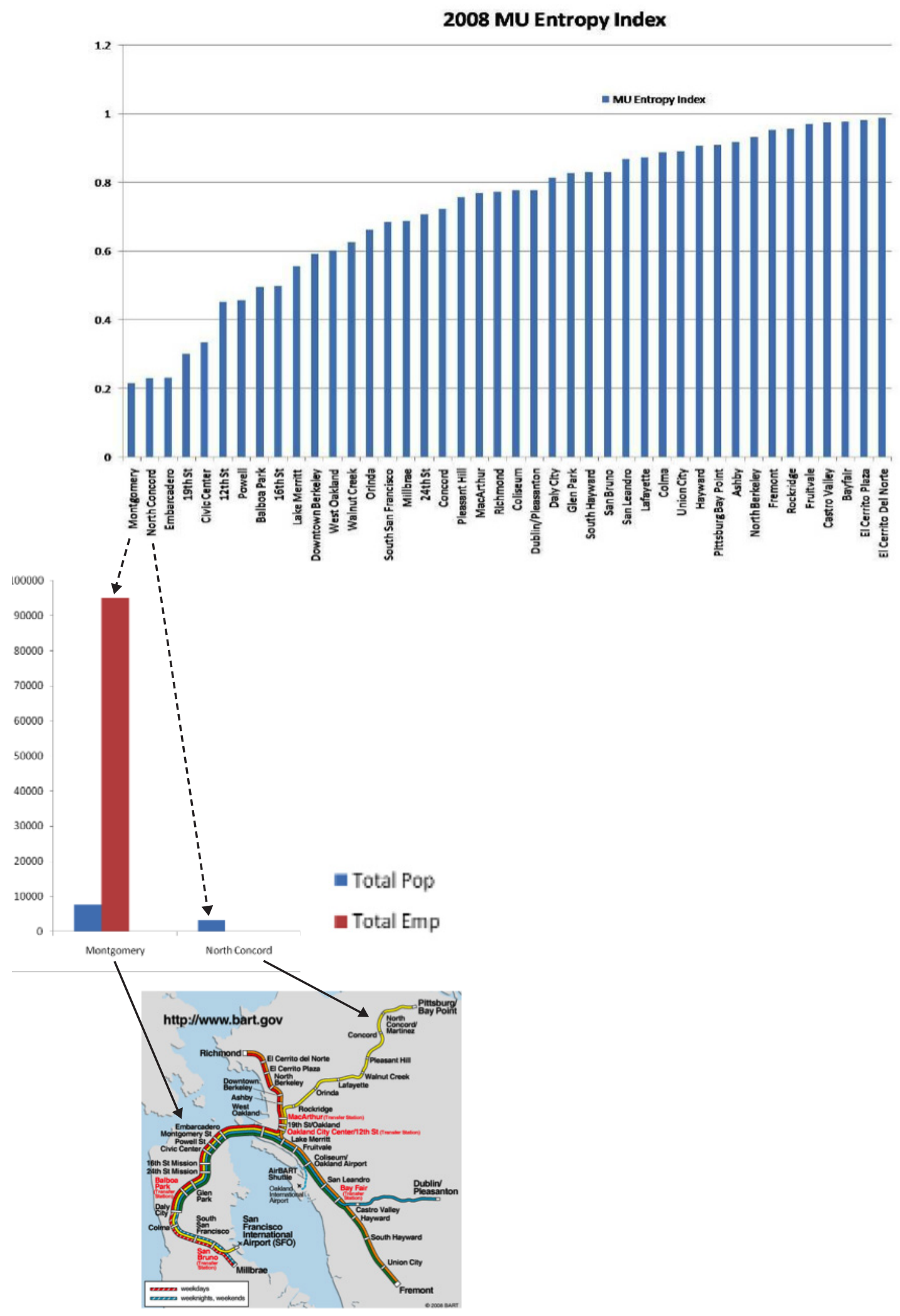

Figure 1: Mixed-use entropy index of BART stations, 2008

Sources: Data from Fehr and Peers Associates (2008) and BART (2008). Map from BART (2010). 
Figure 1 illustrates how entropy indices can hide key land-use activity characteristics. In this example, similar "entropy" scores are obtained for both a downtown San Francisco BART station (Montgomery) and an overwhelmingly suburban residential station (North Concord). As shown in the inset bar chart showing employment (red) and population (blue) for these two stations, similar entropy scores are calculated because both areas have one predominant land use-downtowns are mostly employment, while bedroom communities are mostly residential.

In sum, this type of measure of land-use entropy, or diversity variable, has relatively low relevance to actually inform policy, let alone disaggregate level research and diagnosis of current conditions. While it can indicate whether land-use mixture matters, it cannot tell us how to improve the mixture of uses, such as whether there is a need for more housing, jobs, retail, etc.

\section{Zonal density variable}

The density variable dimension, or activity intensity, has always been an attractive measure for planners as it is relatively easy to gather, interpret, and act upon. However, Ewing and Cervero (2010) find "surprisingly...population and job densities to be only weakly associated with travel behavior once these other variables are controlled" (e.g., VMT elasticities of -0.04 for household or population density and 0.00 for job density). This is likely due to the fact that high-density areas are often associated with other important factors that influence travel behavior, such as the presence of sidewalks, frequent bus service, and parking scarcity.

\section{Zonal design variable}

While not often distinguished in the literature, there are really two aspects of design: 1) functional/ operational, and 2) urban form. In their 2010 meta-analysis, Ewing and Cervero (2010) focus more on functional measures of design, such as zonal measures of intersection density (-0.12 elasticity on VMT), and percentage of four-way intersections $(-0.12 \%$ elasticity on VMT). While they find significant, but limited, associations with walking rates, this is arguably a scale too coarse to fully understand which urban form/aesthetic built environment factors may truly influence people's choice to walk, let alone bicycle.

\section{Analytical approach: Developing new measures of the built environment toward individual access corridor (IAC) analyses}

This section provides a brief overview of the transit access mode choice study used to ground the exploration and development of the new measures of the built environment discussed in this paper (essentially the independent variables for statistical analyses). For more information, see Appleyard (2013).

\subsection{Statistical model and dependent variables}

This analysis is based primarily on a relatively standard intercept transit ridership travel survey-the 2008 Station Profile Survey for the San Francisco Bay Area Rapid Transit (BART) system.

\subsection{MNL modeling}

The new measures discussed below were tested by applying them toward a multinomial logit (MNL) predictive analysis estimating the likelihood an individual will choose a specific rapid transit access mode out of a set of five choices: walk (WALK), bicycle (BIKE), ride a bus (BUS), drive a car alone (CAR), or be driven and dropped off (CARDO). MNL models are based on the basic theory that each traveler $n$ 
is assumed to have a set of travel mode choices, each with its own utility $U$ in which is the utility of the $i$ th mode for the $n$th traveler (Ben-Akiva and Lerman 1985; Train 2009). Furthermore, each traveler's utility is assumed to consist of an observed component Vin plus an unobserved component ein. Below is a representation of the MNL model used in this research to determine the probability of a person choosing to drive a car alone (CAR) to access rapid transit.

$$
P\left(C A R_{n}\right)=\frac{e^{V_{C A R n}}}{e^{V_{W A L K n}}+e^{V_{B I K E n}}+e^{V_{B U S n}}+e^{V_{C A R n}}+e^{V_{C A R D O n}}}
$$

where:

$V_{i n}=$ Constant $_{i}+\beta 1^{\prime}$ UEin $+\beta 2^{\prime}$ PATn

$i=$ mode;

$n=$ decision maker;

$\beta_{1}^{\prime}=$ a row vector for the unknown parameters of the urban environment $(U E)$ variables;

$\beta_{2}^{\prime}=$ a row vector for the unknown parameters of the personal attribute $(P A T)$ variables;

$U E_{\text {in }}=$ a column vector for the urban environment variables (land-use activity, transport access and Perceptual Qualities of the Urban Environment) for each alternative mode $i$ and each decision maker $n$;

$P A T_{n}=$ a column vector for the personal attribute variables of each decision maker $\mathrm{n}$ (gender, income, race, etc.).

\subsection{New measures of the built environment: key independent variables for MNL models of transit access mode choice}

The following is an itemized discussion of new built environment measures (i.e., the independent variables for the MNL predictive model analysis). The measures are based on geospatial calculations using a myriad of special data from various sources.

\subsubsection{Characteristics of the sample population and stations destinations}

This study focuses on morning work commuters traveling between home and the respective rapid rail (BART) stations. These stations are located in the inner (western) portions of San Francisco East Bay Area counties (Alameda and Contra Costa). Finally, this study focuses on stations 1) with auto parking on station property (to control for relatively equal access by all modes) and 2) located outside central business districts (to isolate out confounding effects of downtowns such as congestion, parking scarcity, etc.).

\subsubsection{Creating the linear individual access corridors}

Figure 2 illustrates the application of the individual access corridor (IAC). In brief, the IACs were programmed to capture detailed information for thousands of survey respondents using Python and Visual Basic language within ESRI's GIS software, following these steps :

1. Respondent home origins were geo-located;

2. Then, the shortest (least distance) appropriate routes were estimated for each individual to the rapid transit station specified in their surveys. For bicyclists and pedestrians, for example, pedestrian and bicycle paths were geocoded by hand and freeways were excluded; 
3. 200-foot IAC buffers were created to capture and calculate such things as the average size of the parcels, the proportions of specific land uses along each route, etc.

200-foot buffers were used out of necessity to efficiently process thousands of paths as new measures were being tested. Along these lines, the measurement methods were designed to be intentionally scalable so that they would not change dramatically if a larger buffer were to be used. To support the rationale of using the shortest estimated route between respondents' homes and their respective transit stations, only morning commute trips were used, as these are purposeful and time-sensitive, and thus are less likely to deviate from shortest routes. Winters et al. (2010) researched the amount of deviation drivers and cyclists made, finding that "Regardless of mode, people do not detour far off the shortest route: detour ratios (actual distance/shortest distance) were similar, with $75 \%$ of trips within $10 \%$ of the shortest distance and at least $90 \%$ within $25 \%$. We can certainly assume, however, that bicyclists would prefer routes with traffic-calming features, lanes, and signage. Future research using these methods should seek to address this.

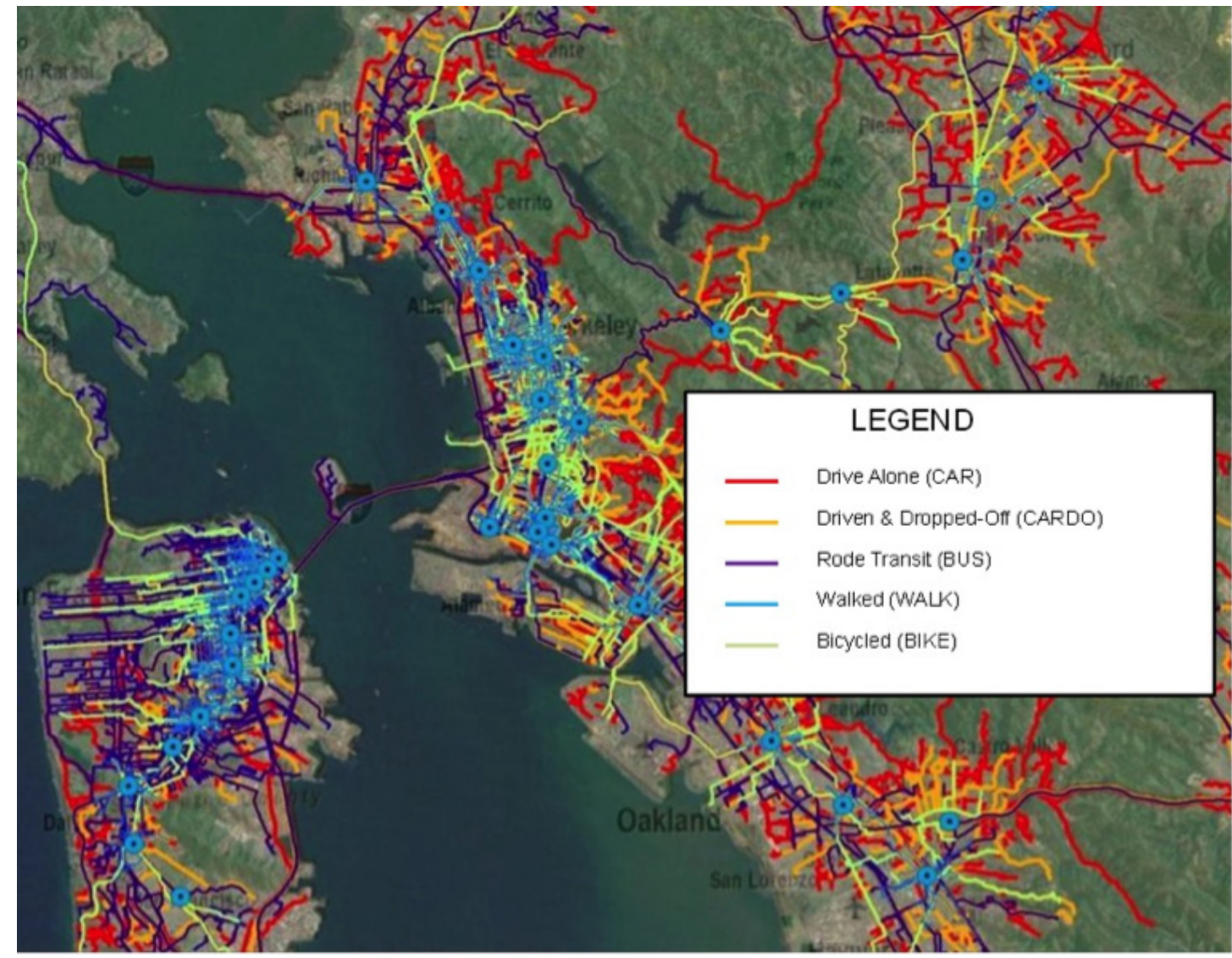

Figure 2: This image shows the thousands of likely paths that were geolocated, from home origin to SF Bay Area BART station destinations, by mode, based on the 2008 BART Station Profile Survey (see legend). Source: Author.

As a linear unit of measure is arguably more appropriate for analyzing a person's travel experience, the IAC therefore provides new capabilities to measure the built environment for travel behavior research, 
and thus enables refinement of the conventional D-variable framework currently dominating the literature. Building on work in Appleyard (2011), the following is introduced as a new set of built environment components for travel behavior research, referred herein as the " 3 As" of the urban environment. As shown in Figure 3, they are:

- Land-use activity: Refers to the activities encountered along the route. These are predominately related to existing land uses but can also incorporate other types of activities, such as crime.

- Transport access: Refers to the physical and functional components of the transportation system (street design and performance, transit service, parking, etc.) that facilitate access.

- Urban aesthetics: Also referred to in the literature as "urban design," or the "perceptual qualities of the urban environment" (Ewing \& Handy 2009)

Figure 3 provides a conceptual diagram of the new, 3-A components of the built environment (access, activity, aesthetics), showing current, D-variable measures (in black), new IAC measures (dark red), and future measures (light red). As we might expect, these new components and measures overlap and complement current D-variable measures.

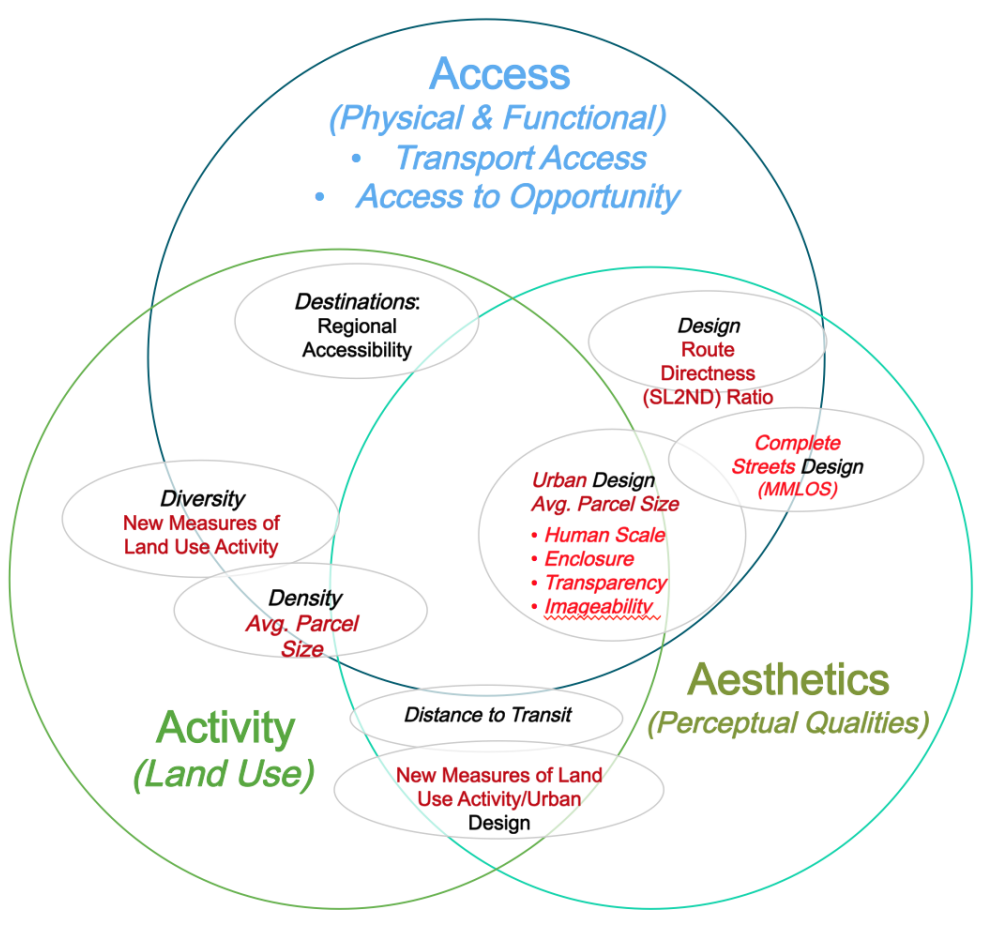

Figure 3: The 3 As of the urban environment. A conceptual diagram of the new, 3-A components of the urban environment (access, activity, aesthetics), showing the conceptual location current D-variable measures (in black), new IAC measures (dark red), and future measures that could be developed (light red).

Urban aesthetics: Average parcel size

Average parcel size is an important measure to emerge from this research as it provides a relatively easyto-obtain replicable and relevant proxy measure of urban aesthetics - a dimension mostly ignored in the conventional D-variable framework. With advances in technology the past few years, parcel geometry has become increasingly recognized as a useful measure of urban form (Lee, Moudon, and Courbois 2006); Mitchell Hess, Vernez Moudon, and Logsdon 2001). Furthermore, Ewing and Handy’s (2009) 
survey of urban design experts regarding which urban form qualities they believe have the greatest influence on walking rates, yielded the following aspects: human-scale, enclosure, imageability, transparency, complexity, and tidiness. For example, Ewing \& Handy's (2009) find that narrower buildings, as might be associated with smaller parcels, "define human scale." Finally, Owens (2008) argues that parcel geometry could serve as a replicable and relevant proxy measure for urban aesthetics. Considering all of the above, this research develops and tests various linear measures of parcel geometry to see whether any can effectively and relevantly determine walking and bicycling rates.

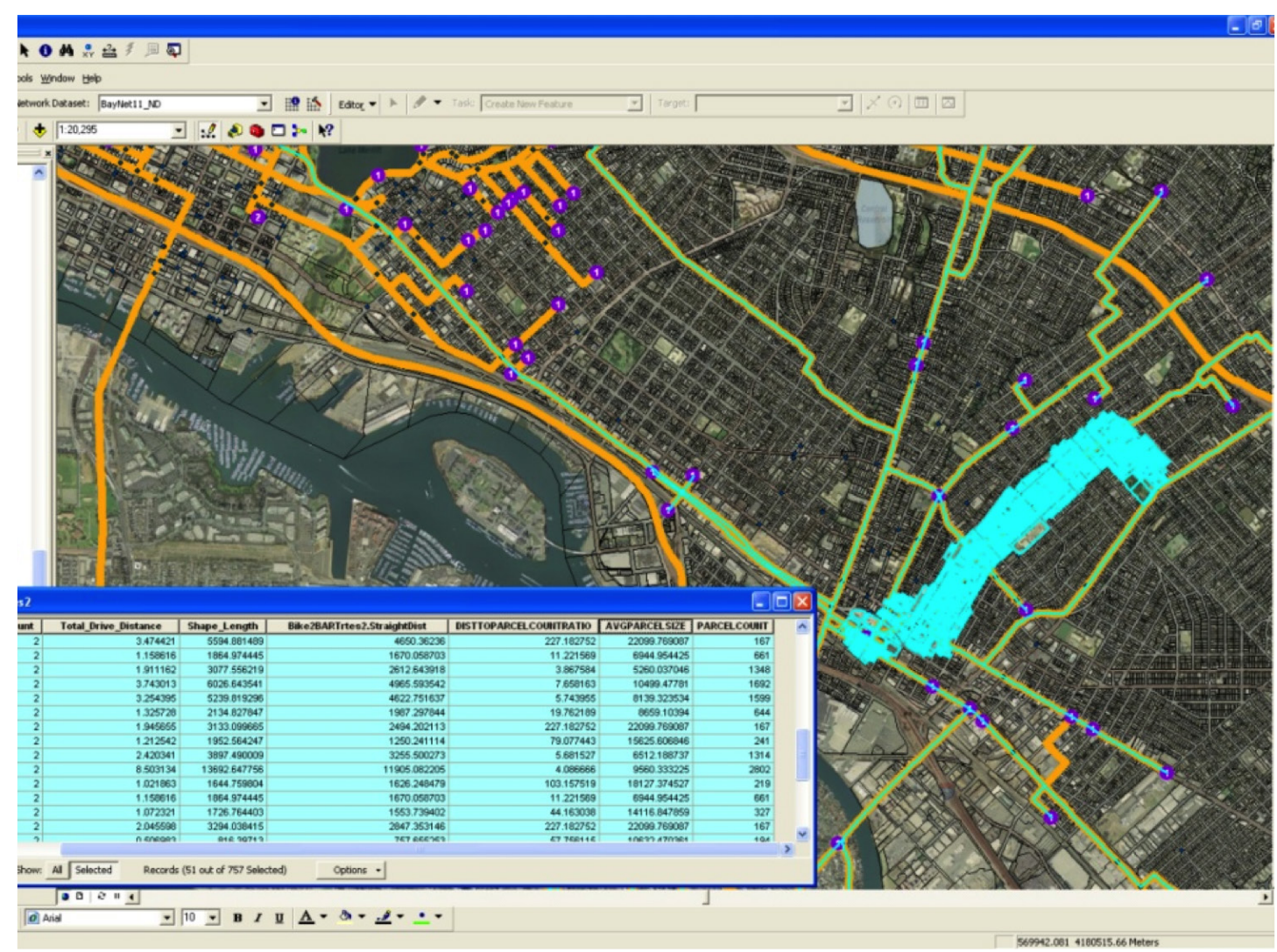

Figure 4: Calculating average parcel size along the IACs. This figure shows one of the key steps for calculating the average parcel size (APS). This image shows a selection of parcels along one individual's likely route to the Fruitvale BART Station (this calculation programmed to be conducted for thousands of survey respondents. It is important to note that to properly capture APS, one needs to select the entire parcel intersecting the IAC —including the portion that lies outside the buffer. Otherwise there will not be any variation in the measure between individuals, and the differing scale of development along the route will not represent the surrounding community context.

After testing various measures of parcel geometry (including parcel counts and a parcel/distance ratio), the measure chosen for further evaluation was average parcel size. To make sure this is a relevant measure of urban aesthetics, it is important to first select parcels with land uses that best reflect building form-in this case, residential and retail parcels. 
Specifically, the average parcel size (APS) along the respondent's estimated IAC route is calculated as follows:

1. Combine land-use data with the GIS parcel data.

2. Examine all land-use categories, selecting the land uses that best reflect the urban aesthetics of building form. For this study, residential and retail parcels were chosen.

3. Create an IAC buffer of a particular size around the respondent's estimated route.

4. Select the parcels intersecting with the IAC buffer. It is important not to cut off the parcel area outside the buffer, as this would discount large parcels one passes.

5. Finally, to arrive at the average parcel size (APS) of an individual's IAC, calculate the combined square footage of all the parcels, and then divide that total by the number of parcels selected.

Land-use activity: Taking advantage of parcel-level land-use information along a linear unit of measure

An added benefit of this linear IAC approach uses fine-grained, parcel-level data. Land-use activity analyzed at the parcel level (instead of the zonal level) likely provides a more appropriate ecological unit of analysis to examine the influence of land-use patterns on travel behavior, especially walking and bicycling.

As is the case in many regions, a key obstacle is that regional planning agencies (in this case, the Association of Bay Area Governments, or ABAG) used many (72) land-use categories, presenting a challenge to achieve both a manageable, and yet meaningful analysis (M\&M) of how land-use activity influences travel behavior. In response, a first step in this research was to further categorize land-use activity into a more manageable number of groups (12), while maintaining their meaning and relevance toward analysis and policy guidance. (Such principles dealing with management and meaning will be increasingly needed by researches working with ever larger and complex datasets.)

As a goal of this study is to better understand urban aesthetics, as well as activity characteristics of the built environment, that are important to pedestrians and bicyclists, two grouping criteria were used: 1) The level of "personal service utility" a land-use activity may serve a morning commuter, and 2) how similar (or different) the urban aesthetics of each of the land-use classifications may be to each other.

Figure 5 provides an example of how this categorization process was applied. Consider a coffee shop, a library, and a golf course. To the morning commuter, the coffee shop likely offers a greater personal service utility than the library or a golf course. The coffee shop was therefore placed in the Small Retail/Mixed-Use category. 


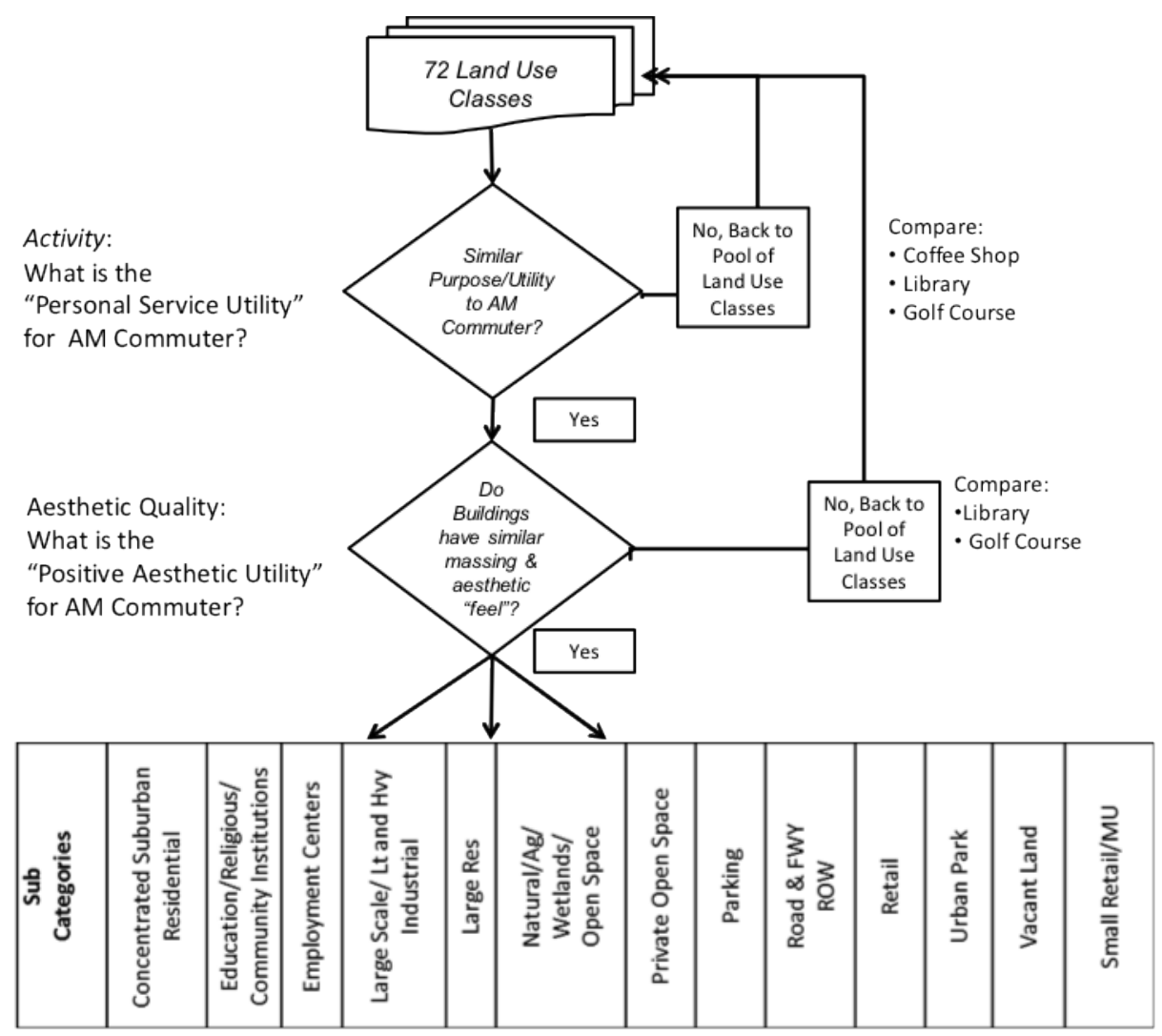

Figure 5: Iterative Decision Process for Grouping Land Use Classifications to Capture Both Activity Utility and Urban Aesthetics

When distinguishing between the library and the golf course on the urban aesthetic criteria, the golf course was placed in the category "Private Open Space," while the library was placed in a category for community institutions.

Out of this approach, four ways to calculate land-use activity along a linear spatial unit of analysis (the IAC) were identified as follows:

- Parcel-based

1. Land-use proportion (LUP): The proportion of the parcel area of a certain land-use category that intersects and is captured within an individual's access corridor.

2. Land-use distance (LUD): The absolute distance of a certain land-use category along an individual's access corridor.

- Point-based

3. Land-use count density (LUCD): A point measure representing the overall number of that activity along an IAC, divided by the distance.

4. Land-use dummy variables (LUDV): A measure representing the presence of an activity, rather than the overall number of that activity, along an IAC.

Determining which of these land-use activity measures to use depends on the types of questions being asked. For land-use categories that present a larger impact on the urban aesthetic experience of pedestrians and bicyclists, such as the amount of land devoted to parking lots and road ROW, either the land- 
use proportion (LUP) measure or land-use distance (LUD) measure could be used. But using such a measure for all land uses could miss the importance of a smaller, human-scale land-use activity, serving a personal service utility.

Consider the example of a coffee shop. A morning commuter may greatly appreciate the opportunity to easily obtain coffee on the way to work. However, an individual likely needs only one (maybe two) coffee shop choices to satisfy their personal service utility needs. Therefore, it makes sense to code such a land-use activity as a dummy variable (as opposed to the proportion or distance along the route), as a person is likely indifferent to whether there are three coffee shops or thirty along their individual access corridor.

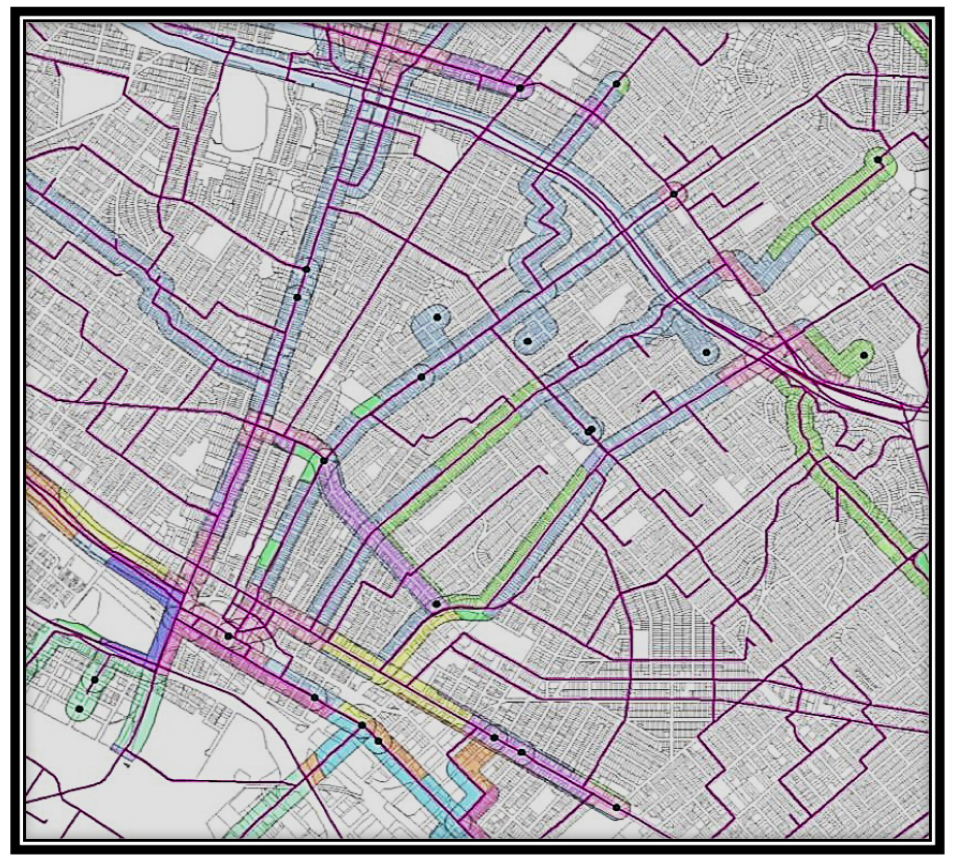

Figure 6: New IAC land-use measures in action. This figure shows how the various land use categories are selected within the IAC method. From this, measures of land-use proportion (LUP) and land-use distance (LUD) can be calculated.

Therefore, for use in this particular individual access corridor analysis, measures of land-use activity chosen for further testing were the land-use proportion (LUP) and land-use dummy variable (LUDV). It is worth noting that for future applications in district/zonal-level analyses, or when using point geo-located events (such as criminal activity or pedestrian/bicycle crashes) the land-use count density (LUCD) measure should be used. Research currently under way on the effects of criminal activity and pedestrian and bicycle casualties on mode choice use this LUCD measure.

\section{Transport access: Route directness}

In this study, transport access includes the physical/functional aspects of modal amenities, and thus includes characteristics of both the journey, such as route directness, as well as the origin (car availability) and destination (e.g., parking cost, availability.). This study develops and tests a measure of route directness, similar to a measure proposed in concept by Dill (2004) and applied in a similar mode choice analysis by Cervero et al. (2009). In both cases, route directness was calculated by dividing the network distance by the straight-line distance (the closer to 1 , the more circuitous the route between home origin and station destination). One concern about this manner of calculation is that greater route directness 
becomes negatively related to walking and bicycling, which is counter-intuitive. In order to create a positive relationship between route directness and walking and bicycling, this study uses the following steps to calculate a straight-line-to-network-distance (SL2ND) ratio:

1. First, using a customized procedure coded in Python, ESRI's Network Analyst was used to calculate the network (and then straight-line) distances between geo-coded home origins and the station destinations

2. Next, the straight-line distance was divided by the straight-line distance between home and station, thereby creating a 0-1 measure of route directness would be positively related to walking and bicycling (the closer to 1 the more direct the route between home origin and station destination).

\section{$3 \quad$ Analytical results}

\subsection{Model results}

Using BioGeme software (Bierlaire 2003) and controlling for important socio-demographic and station destination characteristics (parking cost, availability, etc.), the results of the final model (see Table 1) demonstrated robust model qualities (adjusted rho-squared of 0.558 ) by exhibiting relatively consistent (reliable) results throughout multiple model runs with minor changes to the number of observations, varying variable and parameter combinations, etc. The following is a synopsis of findings discussed in further detail in Appleyard (2012).

\subsubsection{Descriptive statistics of the sample}

The sample population for the final model includes 5,694 respondents, 943 (15\%) of whom identified themselves as either Black or Hispanic/Latino and not White. Other descriptive statistics for this final sample are as follows:

- The median station entry time was 8:15 AM, near the mid-point of the morning commute peak.

- The median average parcel size (APS) along these travelers' IACs is 13,331 square feet, reflecting a moderate suburban character.

- The median SL2D ratio is 0.79 , reflecting relatively direct paths and street connectivity.

The number of individuals in the sample, by mode and percentage of total, are as follows: walk $(2,157$ or $35.23 \%$ ); bicycle (492 or $8.04 \%$ ); rode bus ( 492 or $8.04 \%$ ); drove alone (2,848 or $46.52 \%$ ); were driven and dropped off ( 509 or $8.31 \%$ ). As these are commuters traveling to stations with parking, this is a reasonable profile of station users. 


\begin{tabular}{|c|c|c|c|c|c|c|c|c|c|c|c|c|c|c|c|c|c|c|c|c|c|c|c|}
\hline \multirow{2}{*}{ 列。 } & 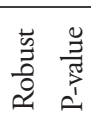 & $\left|\begin{array}{|c|}* \\
0 \\
0 \\
0 \\
0\end{array}\right|$ & & & & & \begin{tabular}{l}
$*$ \\
\multirow{*}{*}{} \\
8 \\
0
\end{tabular} & $\begin{array}{l}* \\
8 \\
8 \\
0\end{array}$ & $\begin{array}{l}\text { 类 } \\
8 \\
0 \\
0\end{array}$ & \begin{tabular}{lll}
7 \\
\hdashline \\
0
\end{tabular} & \begin{tabular}{l|}
$*$ \\
\multirow{*}{*}{} \\
8 \\
0 \\
0
\end{tabular} & $\begin{array}{l}\stackrel{*}{*} \\
\stackrel{0}{0}\end{array}$ & 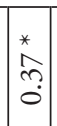 & \begin{tabular}{|c|}
$*$ \\
$*$ \\
0 \\
0 \\
0
\end{tabular} & $\begin{array}{l}1 \\
8 \\
0 \\
0\end{array}$ & ปิ & \begin{tabular}{|l|}
$*$ \\
$*$ \\
0 \\
0 \\
\end{tabular} & $\begin{array}{l}\stackrel{*}{*} \\
\stackrel{8}{8} \\
0\end{array}$ & \begin{tabular}{l|}
$*$ \\
$\stackrel{*}{*}$ \\
8 \\
0 \\
0
\end{tabular} & 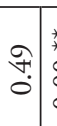 & $\begin{array}{l}* \\
0 \\
8 \\
0 \\
0\end{array}$ & $\begin{array}{l}-\infty \\
\infty \\
0\end{array}$ & \\
\hline & 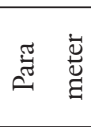 & $\tilde{\sigma}$ & & & & & $\begin{array}{l}\overrightarrow{0} \\
+ \\
\dot{T}\end{array}$ & $\begin{array}{l}\infty \\
\stackrel{\infty}{r}\end{array}$ & $\begin{array}{l}0 \\
\stackrel{0}{1} \\
i\end{array}$ & \begin{tabular}{l|l}
$\tilde{\vdots}$ & $\vdots$ \\
$\hat{n}$ & $\vdots$
\end{tabular} & 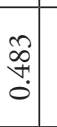 & 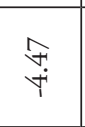 & $\stackrel{\overbrace{}}{\oplus}$ & $\begin{array}{c}0 \\
\dot{\sigma} \\
1\end{array}$ & \begin{tabular}{l}
\multirow{7}{*}{} \\
$\stackrel{1}{1}$
\end{tabular} & $\stackrel{m}{m}$ & \begin{tabular}{|c|}
$n$ \\
$\bar{m}$ \\
$\grave{i}$ \\
1
\end{tabular} & $\begin{array}{c}\widetilde{1} \\
\infty \\
0 \\
0\end{array}$ & $\begin{array}{l}\text { बे. } \\
\stackrel{0}{0}\end{array}$ & $\begin{array}{l}\beth \\
\Xi \\
0 \\
0\end{array}$ & 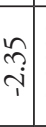 & 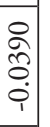 & \\
\hline \multirow{2}{*}{ 胥 } & 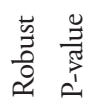 & $\mid \begin{array}{l}* \\
0 \\
0 \\
0 \\
0\end{array}$ & $\stackrel{*}{*}+$ & 足 & & \begin{tabular}{l|}
$\stackrel{*}{*}$ \\
8 \\
0 \\
0
\end{tabular} & $\mid$\begin{tabular}{l}
$*$ \\
\multirow{*}{*}{} \\
0 \\
0 \\
0
\end{tabular} & $\hat{\tilde{o}}$ & తి & 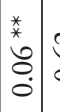 & 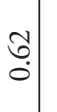 & $\stackrel{*}{*}$ & $\begin{array}{l}\stackrel{+}{\hat{2}} \\
0 \\
0\end{array}$ & $\tilde{0}$ & $\begin{array}{l}* \\
\stackrel{*}{*} \\
\stackrel{+}{0} \\
\end{array}$ & 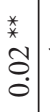 & $\mid \begin{array}{c}\infty \\
\stackrel{\infty}{+} \\
\stackrel{0}{0}\end{array}$ & $\begin{array}{l}\stackrel{*}{*} \\
\stackrel{*}{0} \\
0\end{array}$ & \begin{tabular}{l}
$\stackrel{*}{*}$ \\
0 \\
\hdashline \\
0
\end{tabular} & \begin{tabular}{l|}
$*$ \\
$⿱ *$ \\
\hdashline \\
$\vdots$ \\
$\vdots$
\end{tabular} & $\begin{array}{l}* \\
* \\
\stackrel{*}{*} \\
\vdots \\
0\end{array}$ & 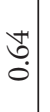 & \\
\hline & 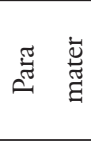 & $\left|\begin{array}{l}n \\
\vdots \\
0 \\
0 \\
0\end{array}\right|$ & 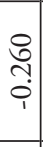 & $\mid$ & & 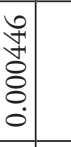 & $\begin{array}{l}\Omega \\
0 \\
0 \\
0 \\
0\end{array}$ & $\begin{array}{l}\stackrel{+}{\mathrm{n}} \\
\stackrel{\text { no }}{i}\end{array}$ & $\begin{array}{l}\infty \\
\overrightarrow{\widetilde{c}} \\
i \\
i\end{array}$ & $\underset{7}{\stackrel{7}{-}}$ & $\begin{array}{l}0 \\
0 \\
\vdots \\
\vdots \\
\vdots \\
1\end{array}$ & $\tilde{\tilde{r}}$ & $\begin{array}{c}a \\
\infty \\
0 \\
\vdots \\
\vdots\end{array}$ & $\begin{array}{l}+ \\
\infty \\
i \\
i\end{array} \mid$ & 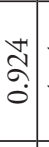 & $\begin{array}{c}\underset{t}{0} \\
+\end{array}$ & $\mid$\begin{tabular}{l}
\multirow{2}{*}{} \\
0 \\
0 \\
0 \\
1
\end{tabular} & 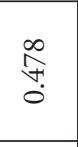 & 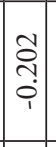 & 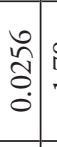 & \begin{tabular}{c|c}
$\infty$ \\
\hdashline \\
-
\end{tabular} & 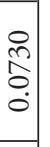 & \\
\hline \multirow{2}{*}{ 帘 } & 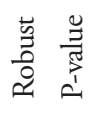 & & \begin{tabular}{l}
$*$ \\
\multirow{*}{*}{} \\
8 \\
0 \\
0
\end{tabular} & \begin{tabular}{|l|} 
\\
$*$ \\
8 \\
0 \\
0
\end{tabular} & & \begin{tabular}{l}
. \\
8 \\
8 \\
$\vdots$ \\
\multirow{*}{*}{}
\end{tabular} & & & & & & & & & & & & & & & & & \\
\hline & 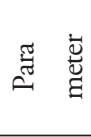 & 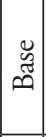 & $\begin{array}{l}\hat{0} \\
\hat{n} \\
\hat{i}\end{array}$ & $\begin{array}{c}7 \\
\infty \\
0 \\
0\end{array}$ & & 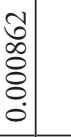 & & & & & & & & & & & & & & & & & \\
\hline \multirow{2}{*}{$\sum_{\infty}$} & 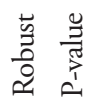 & $\mid \begin{array}{l}* \\
0 \\
0 \\
0 \\
0\end{array}$ & & & & $\stackrel{2}{\circ}$ & & $\begin{array}{l}\stackrel{*}{*} \\
\stackrel{8}{8} \\
0\end{array}$ & ?̊. & \begin{tabular}{l|l}
$*$ \\
$*$ \\
8 \\
0 \\
0
\end{tabular} & $\begin{array}{l}* \\
* \\
0 \\
0 \\
0\end{array}$ & ثّ & $\begin{array}{l}0 \\
\infty \\
0 \\
0\end{array}$ & 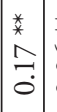 & \begin{tabular}{l}
$*$ \\
$*$ \\
\multirow{*}{*}{} \\
0 \\
0
\end{tabular} & $\begin{array}{l}\widetilde{\sigma} \\
\dot{0}\end{array}$ & $\mid \begin{array}{c}* \\
* \\
n \\
0 \\
0 \\
\end{array}$ & \begin{tabular}{l}
$\stackrel{*}{*}$ \\
8 \\
\hdashline
\end{tabular} & $\tilde{n}$ & $\begin{array}{l}- \\
\stackrel{0}{\circ}\end{array}$ & \begin{tabular}{l}
$*$ \\
$*$ \\
\multirow{2}{*}{} \\
8 \\
$\vdots$ \\
0
\end{tabular} & $\begin{array}{l}\circ \\
\vdots \\
\circ\end{array}$ & \\
\hline & 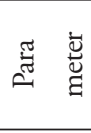 & $\mid \begin{array}{c}0 \\
\tilde{i} \\
\text { }\end{array}$ & & & & $\begin{array}{l}0 \\
0 \\
8 \\
0 \\
0 \\
0\end{array}$ & & $\underset{\stackrel{\infty}{\infty}}{\stackrel{\infty}{n}}$ & $\frac{m}{\tilde{c}}$ & 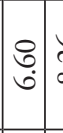 & 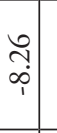 & $\begin{array}{l}\hat{S} \\
\stackrel{i}{i}\end{array}$ & $\mid \begin{array}{l}8 \\
0 \\
0 \\
1\end{array}$ & $\begin{array}{l}0 \\
\stackrel{j}{二}\end{array}$ & $\begin{array}{c}\infty \\
\infty \\
\dot{\sim}\end{array}$ & $\begin{array}{l}3 \\
i \\
i\end{array}$ & $\left|\begin{array}{|l}\overrightarrow{\widetilde{b}} \\
\vdots \\
i\end{array}\right|$ & ஸे. & 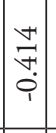 & $\begin{array}{l}0 \\
+ \\
2 \\
0 \\
0\end{array}$ & $\begin{array}{l}\tilde{c} \\
\dot{T}\end{array}$ & $\begin{array}{l}n \\
0 \\
0 \\
0 \\
0\end{array}$ & \\
\hline \multirow{2}{*}{ 却 } & 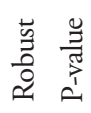 & \begin{tabular}{l}
$*$ \\
\multirow{2}{*}{} \\
0 \\
0 \\
0
\end{tabular} & & & $\begin{array}{l}* \\
* \\
8 \\
8 \\
0\end{array}$ & & $\mid$\begin{tabular}{l}
$*$ \\
$*$ \\
\multirow{*}{*}{} \\
0 \\
0 \\
\end{tabular} & ֶิ & $\begin{array}{l}\text { 类 } \\
\vdots \\
0 \\
0\end{array}$ & 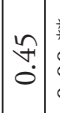 & $\begin{array}{l}* \\
* \\
8 \\
0 \\
0\end{array}$ & $\begin{array}{l}\stackrel{\leftrightarrow}{0} \\
\stackrel{0}{0}\end{array}$ & $\overrightarrow{\tilde{o}}$ & \begin{tabular}{|c|}
$*$ \\
$*$ \\
8 \\
0 \\
0 \\
\end{tabular} & \begin{tabular}{l}
$*$ \\
\multirow{2}{*}{} \\
0
\end{tabular} & ֶָ. & 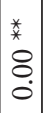 & $\begin{array}{l}\stackrel{*}{*} \\
\stackrel{8}{0} \\
0\end{array}$ & \begin{tabular}{|l|} 
\\
$*$ \\
\multirow{*}{*}{} \\
8 \\
0 \\
\end{tabular} & : & \begin{tabular}{l|l}
$*$ \\
$*$ \\
8 \\
8 \\
$\vdots$
\end{tabular} & $\begin{array}{l}* \\
* \\
8 \\
8 \\
0\end{array}$ & \\
\hline & 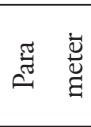 & $\underset{r}{\stackrel{1}{n}}$ & & & 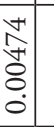 & & 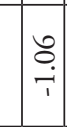 & $\stackrel{\infty}{\stackrel{f}{*}}$ & $\begin{array}{c}\infty \\
\stackrel{0}{7} \\
1\end{array}$ & $\left|\begin{array}{l}\infty \\
\infty \\
0 \\
0\end{array}\right|$ & $\begin{array}{l}\text { त్ } \\
0\end{array}$ & $\begin{array}{l}\text { ôे } \\
\text { on } \\
\text { în }\end{array}$ & $\begin{array}{l}0 \\
\text { i } \\
\text { i }\end{array}$ & $\begin{array}{c}\hat{m} \\
\overline{1}\end{array}$ & $\begin{array}{l}\stackrel{0}{\mathbb{N}} \\
\hat{0}\end{array}$ & $\underset{i}{N}$ & \begin{tabular}{l}
0 \\
\multirow{0}{*}{} \\
$\vdots$ \\
$i$ \\
1
\end{tabular} & $\stackrel{\overbrace{}}{\stackrel{\overbrace{}}{r}}$ & 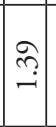 & $\begin{array}{l}n \\
\vdots \\
\vdots \\
\dot{0}\end{array}$ & 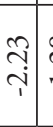 & 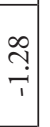 & \\
\hline & 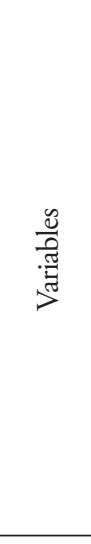 & 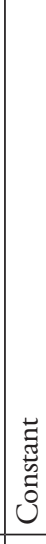 & 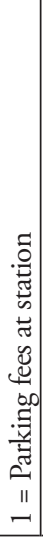 & 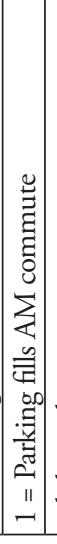 & 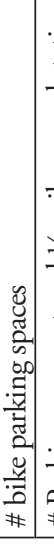 & 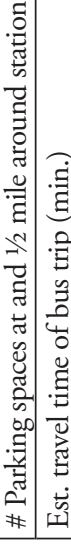 & 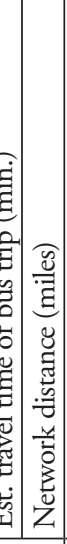 & 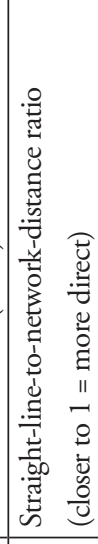 & 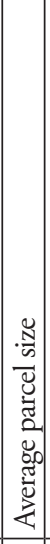 & 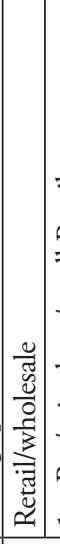 & 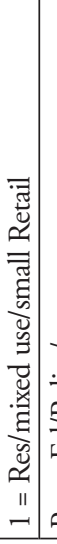 & 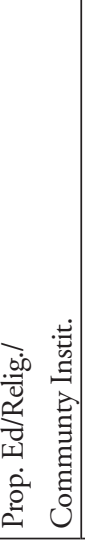 & 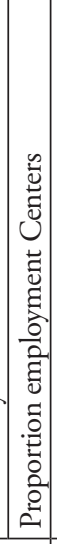 & 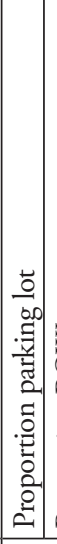 & 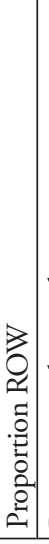 & 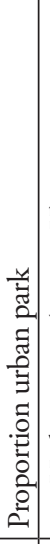 & 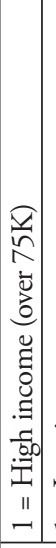 & 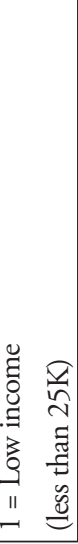 & $\mid$ & 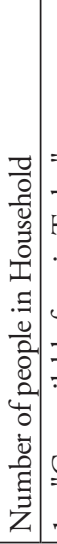 & 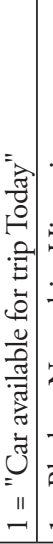 & 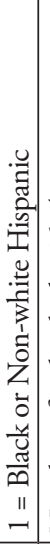 & 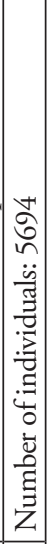 \\
\hline & 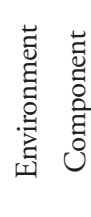 & & & & 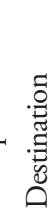 & 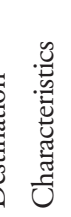 & & 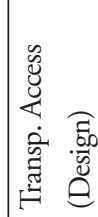 & 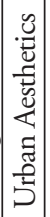 & & & 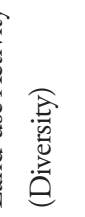 & & & & & & 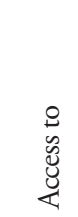 & 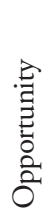 & 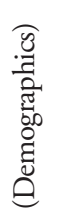 & & & \\
\hline
\end{tabular}




\subsubsection{Discussion of model results}

Discussion of potential issues of collinearity

As with most statistical models, some of the parameter coefficients may have collinear relationships. To test whether one parameter coefficient is significantly different than another, BioGeme provides a table of the correlation of coefficients $(\mathrm{CoC})$, which matches each coefficient against the other, and providing test statistics (robust p-value) of whether one parameter coefficient is significantly different than another. The $\mathrm{CoC}$ table for this model presents covariance calculations for 2,775 pairs of coefficients. 1,789 of these pairings (or 64\%) have a robust p-value below .2, meaning it is possible to reject the null hypothesis that one parameter coefficient equals another at a $20 \%$ confidence level for $64 \%$ of the parameter pairings in the model. Furthermore, 2,233 (or 80\%) are below .5.

Some of the collinear relationships make intuitive sense; others require more exploration to be better understood. For example, average parcel size and the proportional presence of parking lots and public right of way show a collinear relationship. This makes sense as larger parcels are often associated with more suburban, auto-oriented areas. In future analyses, it would be prudent to explore using one of these variables over the others and/or using instrument variables that would be related to one of these variables, but not the others.

\section{Model results}

Consistent with previous studies, a selection of the results are outlined below as they 1) represent the new components of the built environment developed in this study (urban aesthetics, land-use activity, and transport access), and 2) they reveal new information about the relationship of the built environment and the choice to bicycle or walk. The following is a brief synopsis of the findings discussed in further detail in Appleyard (2012).

\section{Urban aesthetics: Average parcel size}

Average parcel size (APS) consistently shows a significantly negative association with the likelihood that a person will either walk (-.109) or bicycle (-.18) to access rapid transit. Therefore, parcel geometry seems to serve as a promising proxy measure for urban aesthetic qualities important to walking and bicycling rates. It can also serve as a useful proxy measure for intensity of development, instead of, or to augment, measures of density.

\section{Land-use activity: Small retail/mixed use}

The presence of small retail/mixed-use opportunities (e.g., coffee shops) has a significant positive association with the likelihood one will walk (.483) or bicycle (.627), supporting, in theory, that the ability to satisfy a personal service utility as part of the morning commute matters positively to walking and bicycling rates.

\section{Land-use activity: Proportion of land in parking and ROW}

The strong, negative association between the land-use proportion (LUP) of an individual's access corridor devoted to road right-of-ways (ROW) on walking rates (-3.42) supports the theory that large intersections and roadways discourage walking. Furthermore, the strong negative associations between the likelihood of walking (-9.63) or bicycling (-13.7) with large proportions of land in parking supports the theory that parking lots create unfriendly environments to pedestrians and bicyclists. Combined with other findings, mentioned above, for pedestrians the issue could also be one of few opportunities for servicing personal needs. Bicyclists could have similar issues, but with the added threat posed by drivers entering and exiting driveways. 
Transport access: Straight-line-to-network-distance ratio along individual access corridors

The straight-line-to-network-distance (SL2ND) ratio for this sample is found to have a significant positive association with the likelihood one will walk (3.68) or bicycle (.443), supporting the theory that pedestrians and bicyclists are encouraged by direct paths.

Transport Access: Station car and bicycle parking

As one would expect, there is a statistically significant positive relationship between the number of bicycle and car parking spaces and the likelihood one would bicycle (.00474) or drive (.000862) to the transit station. Also consistent with theory, auto parking fees appear to significantly discourage driving alone (-.507).

\section{Combined findings on urban aesthetics and walking}

Figure 5 illustrates how the combined findings on average parcel size (APS), small retail/mixed use, proportion of land in parking and road right-of-way (ROW) support the theory that certain urban aesthetic qualities may indeed be important toward encouraging walking, as posited in Ewing and Handy's 2009 survey of urban design experts. The findings presented in this paper support their theory that the urban aesthetic qualities of human-scale, enclosure, imageability, transparency, and complexity may indeed be important to walking, and by extension, bicycling as 1) smaller parcels likely have older, "human-scale" buildings 2) that are located closer to the street (giving the street environment a stronger sense of enclosure); 3) have distinct characteristics, emanating senses of imageability); 4) have windows on the ground floor, providing transparency; and finally 5) contribute to a rich sense of visual complexity by creating streetscapes with frequent, narrow buildings with detailed fenestration..

\subsection{Quantitative and qualitative comparison of IAC and xonal D variables}

To further determine whether these new measures are useful in analyses of travel behavior, this paper employs a mixed, quantitative/qualitative approach. First, this paper tests the statistical model performance, comparing models with the new IAC variables against those zonal, $\mathrm{D}$ variables now commonly used in practice. The second approach, which is perhaps more important, is to discuss the theoretical validity and usefulness of these measures in 1) diagnosing issues regarding the built environment and travel behavior, and 2) the usefulness of these new measures in providing relevant guidance for policy interventions.

In addition to improved, albeit modest, model performance, the discussion herein finds that these new measures provide richer, more nuanced information about the built environment that helps in both problem diagnosis and policy guidance. 


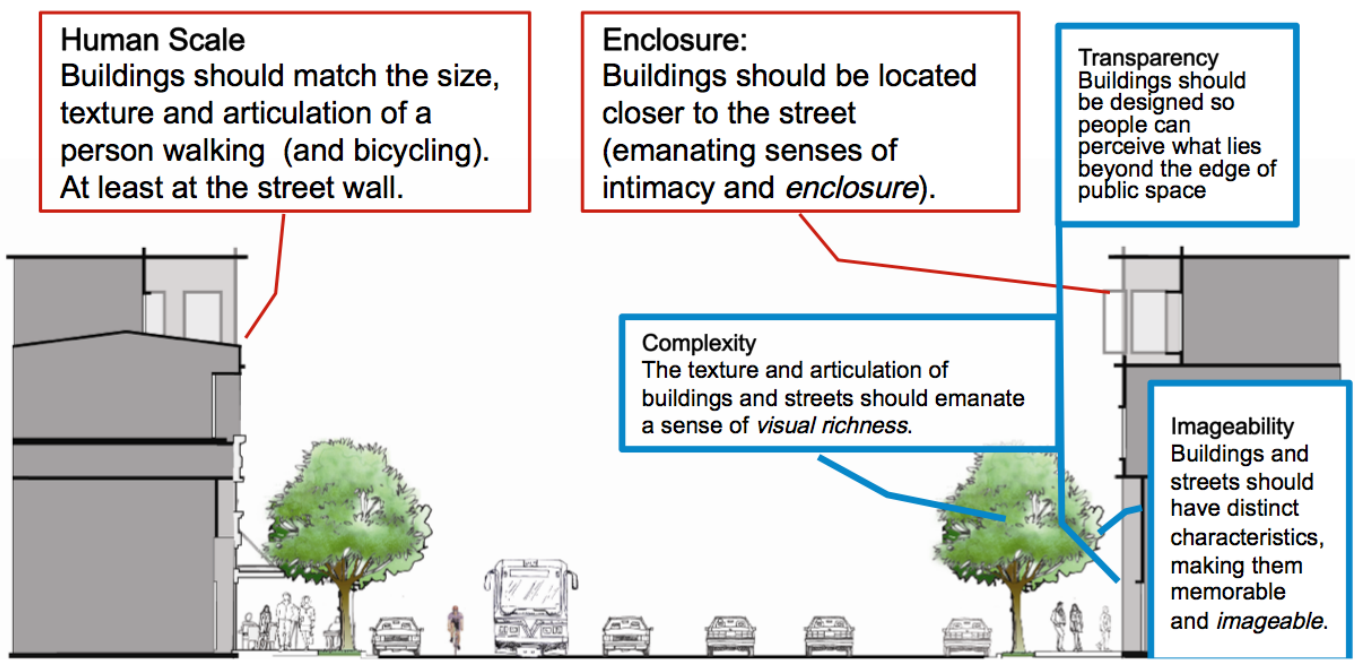

Illustration by Bruce Appleyard, PhD

Figure 7: The combined findings on average parcel size (APS), small retail/mixed use, proportion of land in parking and ROW support the findings of Ewing \& Handy's (2009) survey of urban design experts believed to be important to encouraging walking: 1) buildings that provide a "human scale," 2) are located closer to the street (giving the street environment a stronger sense of enclosure); 3) have distinct characteristics, emanating imageability; and 4) have buildings with windows on the ground floor (transparency) and detailed fenestration, emanating a visually rich sense of complexity.

\subsubsection{Testing models and variables: Adjusted rho-square comparisons}

Recognizing there are other more sophisticated procedures for comparing non-nested models, where different sets of variables replace each other (Clarke and Signorino 2010), a useful, straight-forward procedure is to compare the model's adjusted rho-squares. This works because adjusted rho-squares impose a penalty for adding more explanatory terms (variables and parameters) as opposed to rho-square. Essentially, this is a standardized goodness-of-fit measure which, unlike rho-square, increases only if the new variable, or set of variables, improves the model's performance (Ben-Akiva and Lerman 1985). This is relevant to the analysis in this section, as when comparing Model 1 with Models 2 and 3, the variables decrease from 21 to 15 and the parameters decrease from 75 to 51 .

\section{Standard zonal D variables used for comparison with IAC measures}

Table 2 (within the bold black inset box) lists the standard zonal $D$ variables (calculated within $1 / 2$ mile of a BART station) used for comparison against the new IAC measures developed in this paper. It is worth noting that the station destination is being measured, as opposed to the zone around the home origin, as is often used in practice (Boarnet 2011). Arguably, the characteristics of the destination could have a stronger influence over travel behavior than the home origin.

It is also important to note that these measures are not perfect equivalents of each other, oftentimes differing on what they indicate about the built environment (problem diagnosis) and how they may guide policy (prognosis). In many cases measures, both old and new, overlap with the new components of the built environment outlined in this paper (urban aesthetics, land-use activity, and transport access). For example, average parcel size can serve both as a measure for intensity of development, and thus could be compared with the density variable as well as urban aesthetics - and therefore could also be compared with the design variable (calculated as the number of four-legged intersections within $1 / 2$ mile 
of a BART station).

Model specifications

The various model specifications outlined in Table 2 are described in detail below:

Model 1

This is the final model presented in Table 1 and contains new IAC-based measures for comparison.

Model 2

In Model 2, standard, zone-based entropy measures of land-use mixture, similar to the one presented earlier in Figure 1 of this paper and representing current research practice, replaces the new IAC land-use activity measures representing parcel-level identified land-use categories (using LUDV \& LUP measures).

Model 3: Full complement of zonal D variables (density, diversity, and design)

Model 3 makes the following changes to Model 2:

- Average parcel size is replaced with a more standard zonal measure for the density variable: Population and jobs per acre.

- The individual straight-line-to-network-distance (SL2ND) ratio is replaced with a standard design variable (the number of four-legged intersections within $1 / 2$ mile zone around the station).

The representation of the variables and comparison of the three models is presented in Table 2. 
Table 2: IAC vs. zonal measures: Comparison of access mode choice models

\begin{tabular}{|c|c|c|c|c|}
\hline $\begin{array}{c}\text { Urban/Built } \\
\text { Environment } \\
\text { Components }\end{array}$ & Final Model Variables & $\begin{array}{l}\text { Model 1* } \\
\text { New IAC } \\
\text { Measures }\end{array}$ & $\begin{array}{c}\text { Model } 2^{* *} \\
\text { Standard } \\
\text { Zonal: } \\
\text { Diversity }\end{array}$ & $\begin{array}{c}\text { Model 3*** } \\
\text { Standard Zonal: } \\
\text { Density, Diversity, } \\
\text { \& Design }\end{array}$ \\
\hline \multirow{7}{*}{$\begin{array}{l}\text { Transport Access } \\
\text { (Design) }\end{array}$} & $\begin{array}{l}1=\text { station parking fills for AM } \\
\text { commute }\end{array}$ & $\mathrm{X}$ & $\mathrm{X}$ & $\mathrm{X}$ \\
\hline & $1=$ parking fees at station & $\mathrm{X}$ & $\mathrm{X}$ & $\mathrm{X}$ \\
\hline & \# of bike parking spaces & $\mathrm{X}$ & $\mathrm{X}$ & $\mathrm{X}$ \\
\hline & $\begin{array}{l}\text { \# of parking spaces at station and } 1 / 2 \\
\text { mile around station }\end{array}$ & $\mathrm{X}$ & $\mathrm{X}$ & $\mathrm{X}$ \\
\hline & Est. travel time of bus trip (minutes) & $\mathrm{X}$ & $\mathrm{X}$ & $\mathrm{X}$ \\
\hline & Network distance (miles) & $\mathrm{X}$ & $\mathrm{X}$ & $\mathrm{X}$ \\
\hline & New IAC Measures & & & $\begin{array}{c}\text { Standard Zonal D } \\
\text { Variables: Density, } \\
\text { Diversity, \& Design }\end{array}$ \\
\hline $\begin{array}{l}\text { Transport Access } \\
\text { (Design) }\end{array}$ & $\begin{array}{l}\text { Straight-line-to-network-distance ratio } \\
\text { (0-1, closer to } 1 \text { being more direct) }\end{array}$ & $\mathrm{X}$ & $\mathrm{X}$ & $\begin{array}{l}\# \text { of 4-legged intersections } \\
\text { within } 1 / 2 \text {-mile zone of } \\
\text { station }\end{array}$ \\
\hline Aesthetics (Intensity) & Average parcel size (sq. ft) & $\mathrm{X}$ & $\mathrm{X}$ & $\begin{array}{l}\text { Population \& employment/ } \\
\text { acre (1/2-mile station zone) }\end{array}$ \\
\hline \multirow{4}{*}{$\begin{array}{l}\text { LU Activity } \\
\text { (Diversity) }\end{array}$} & Prop. retail/wholesale (LUP) & $\mathrm{X}$ & \multirow{7}{*}{$\begin{array}{l}\text { DIVERSITY } \\
\text { ZonJHentropy } \\
\text { (1/2-mile station } \\
\text { zone) }\end{array}$} & \multirow{7}{*}{$\begin{array}{c}\text { DIVERSITY } \\
\text { ZonJHentropy } \\
\text { (1/2-mile station zone) }\end{array}$} \\
\hline & $1=$ Small retail/res/mixed use (LUDV) & $\mathrm{X}$ & & \\
\hline & Ed/religious/comm. institution (LUP) & $\mathrm{X}$ & & \\
\hline & Employment centers (LUP) & $\mathrm{X}$ & & \\
\hline \multirow{3}{*}{$\begin{array}{l}\text { LU (Activity/ } \\
\text { Aesthetics }\end{array}$} & Proportion parking lot (LUP) & $\mathrm{X}$ & & \\
\hline & Proportion ROW (LUP) & $\mathrm{X}$ & & \\
\hline & Proportion urban park (LUP) & $\mathrm{X}$ & & \\
\hline \multirow{6}{*}{$\begin{array}{c}\text { Access to } \\
\text { Opportunity/ } \\
\text { Personal } \\
\text { Attributes (PATs) }\end{array}$} & $1=$ High income $($ over $75 \mathrm{~K})$ & $\mathrm{X}$ & $\mathrm{X}$ & $\mathrm{X}$ \\
\hline & $1=$ Low income (less than $25 \mathrm{~K}$ ) & $\mathrm{X}$ & $\mathrm{X}$ & $\mathrm{X}$ \\
\hline & 1 = Male & $\mathrm{X}$ & $\mathrm{X}$ & $\mathrm{X}$ \\
\hline & Number of people in household & $\mathrm{X}$ & $\mathrm{X}$ & $\mathrm{X}$ \\
\hline & $1=$ "Car available for trip today" & $\mathrm{X}$ & $\mathrm{X}$ & $\mathrm{X}$ \\
\hline & 1= Black or nonwhite Hispanic & $\mathrm{X}$ & $\mathrm{X}$ & $\mathrm{X}$ \\
\hline \multirow{2}{*}{ Measures of Model } & Number of observations & 5694 & 5694 & 5694 \\
\hline & Number of parameters & 75 & 51 & 51 \\
\hline \multirow{2}{*}{ Performance } & Final log-likelihood & -3326.315 & -3396.227 & -3470.490 \\
\hline & Adjusted rho-square & 0.558 & 0.552 & 0.542 \\
\hline
\end{tabular}

* Model 1: New measures model (same as the final model)

** Model 2: Standard, zonal measures for diversity (ZonJHEntropy within $1 / 2$ mile of station), replaces the new IAC land-use activity measures.

*** Model 3: New IAC measures are all replaced with standard, zonal measures for diversity (ZonJHEntropy within $1 / 2$ mile of station destination), density (Pop + Emp. Per Acre), and design (\# of 4-legged intersections within 1/2 mile of station).

Comparing land-use activity: Model 1, IAC land-use activity, and Model 2, zonal D variable for land-use activity diversity

Comparing the adjusted rho-squares of the model results presented in Table 3, Model 1 (which includes the new IAC-based land-use activity measures) and Model 2 (with a standard zonal, diversity 
D-variable measure) shows that Model 1 ( 0.558 adjusted rho-square) performs (meaning fits the data) better than Model 2 ( 0.552 adjusted rho-square). From a statistical model performance standpoint, the new IAC land-use activity measures prove useful, albeit modest, refinements over the zonal diversity variable entropy measure currently used in practice. However, from a qualitative perspective, the new IAC measures demonstrate greater promise by telling a much richer story about the influence of the built environment on travel, and how policymakers will want to respond.

As discussed earlier and illustrated in Figure 1, simple measures of land-use entropy, the diversity variable, tell us little about current conditions. While they can indicate whether land-use activity mixture matters, they cannot tell us how to respond - they do not indicate how to improve the mixture of uses, such as whether there is a need for more housing, jobs, retail, etc.

Alternatively, the new IAC measures provide more information on what might be happening in the field. For example, as discussed earlier, the positive significance of small retail/mixed-use opportunities (e.g., coffee shops) on the likelihood one will walk (.483) or bicycle (.627) can be highlighted. Furthermore, the strong negative associations between the land-use proportion (LUP) of an individual's access corridor devoted to roadways (ROW) and large proportions of land in parking lower the likelihood an individual would walk (-3.42 for roadways; -9.63 for parking) or bicycle (-13.7 for parking). These findings support the theory that auto-oriented environments- large areas devoted to parking lots, intersections, and roadways—likely discourage pedestrian and bicycle travel.

Comparing Models 1, 2 and 3: All IAC variables, with all zonal D variables (density, diversity, and design)

Comparing Model 1 ( 0.558 adjusted rho-square) with Model 3 (0.542 adjusted rho-square) reveals the most dramatic improvement in model performance between the new IAC variables and a collection of the standard D variables of density, diversity, and design. (Incidentally, Model 2 has an adjusted rhosquare of 0.552). What contributes to this is the replacement of the new IAC average parcel size (APS) measure and individual straight-line-to-network-distance (SL2ND), in both Models 1 and 2, with standard D-variable measures of:

- A standard density variable measure:

- population + employment per acre, and

- A standard design variable measure:

- number of 4-legged intersections within $1 / 2$ mile of station

While the comparison of the IAC-based land-use activity measures (Model $1-0.558$ adjusted rhosquare) and the standard zonal, diversity D-variable measure (Model $2-0.552$ adjusted rho-square) shows a modest improvement in model performance (but with sound policy relevance), the comparison between Models 1 and 3 highlights a more dramatic improvement the new IAC average parcel size (APS) and individual straight-line-to-network-distance (SL2ND) measures have over standard Dvariable measures of density (pop + emp. per acre within $1 / 2$ mile of station) and design (\# of 4-legged intersections within $1 / 2$ mile of station).

\section{Discussion of relevance toward problem diagnosis and policy guidance}

While some may choose to see the model performance improvements as modest, these results still support the hypothesis that these new, human-scale and linear IAC measures can improve our statistical analyses of the built environment's influence on travel behavior. Furthermore, and perhaps more importantly, from a problem diagnosis and planning/design guidance perspective, these new measures provide even greater policy relevance than the standard zonal measures currently used in practice. This, however, 
is not to say that future models should not include both IAC and standard D-variable measures, as they can in combination provide important information for statistical modeling and policy guidance.

\section{Conclusions, lessons learned, and future steps}

This paper demonstrates that more refined, linear measures can be an improvement on prevailing zonebased D-variable framework (design, density, diversity) commonly used in practice in two important ways: First, they demonstrate an increase in statistical model performance while secondly, and perhaps more importantly, provide richer, more nuanced information relevant to 1) diagnosing the strengths and weaknesses of the built environment for human-scale (pedestrian and bicycle) travel, as well as 2) guide policy and design decisions to increase the likelihood one will walk or bicycle. Specifically, these new, human-scale IAC measures improve our capabilities as follows:

- They more profoundly analyze the influence of land-use activities and synergies, beyond current D-variable measures, such as land-use entropy and "diversity" - shown in this paper to mask important characteristics necessary for reliable analyses of the built environment's influence on travel.

- They allow us to analyze route directness which, combined with the findings on other measures, highlights the importance to pedestrians and bicyclists of narrower (lower proportions in ROW), well-connected streets (higher SL2ND ratios) with fewer parking lots.

- This research provides a series of new measures of urban form aesthetics which, up until now, has rarely been captured for enough survey respondents to be statistically meaningful. The findings related to the new IAC measures highlight the importance of a human-scaled urban aesthetics to human-scale travel (walking and bicycling), as shown in the findings of the influence of smaller parcels; small, personal service retail opportunities; land-use activity mixture and synergies; and narrower, well-connected, pedestrian- and bicycle-friendly streets.

Finally, it is worth noting that this is one of the first travel behavior studies to examine the built environment from origin to destination, as well as to more fully incorporate an examination of the factors increase the possibility that a person will choose to bicycle over other modes.

\subsection{Caveats}

As with any study, there are a few caveats. For example, follow-up surveys with respondents would be useful to precisely determine the exact location of a person's IAC route, as well as other factors, such as personal tastes and preferences, influencing mode choice decisions. In response to this limitation, it should be noted that IAC measures were designed to be scalable without dramatic value changes if a larger IAC buffer was used to capture a wider range of possible routes. This is one of the advantages of using land-use proportion (LUP) measure, instead of the land-use distance (LUD) measure, for example.

Furthermore, it is also important to recognize that these methods were tested in light of morning work trips via rail transit, which embeds unique traveler characteristics (socio-demographic, preferences, etc.) and availability constraints - the system must go where people need to go. It is also important to note that these methods were tested against utilitarian work trips, and the non-work travel, recreational travel may respond differently to these new measures. Nevertheless, as any travel is a linear activity, it makes sense to explore using linear spatial units of measures, as opposed to coarse zones.

Still, it may continue to be important for the profession to apply these measures toward zonal -level examinations of their relationship to travel, as scenario planning efforts often analyze things at a district scale relying on zonal spatial units of analysis. By extension, these measures have been designed as refine- 
ments and complements to conventional $\mathrm{D}$ variables.

\subsection{Closing remarks}

With the advent of new techniques and data sources, we must seek ways to evolve and refine our approaches if we wish to better understand the relationship between the built environment and humanscale travel behavior - especially for those seeking to travel outside protective, vehicular confines-pedestrians and bicyclists - who can more freely engage with the world around them, not only lowering serious environmental impacts but also providing important social benefits such as opportunities for people to interact with each other and build social capital (Appleyard et al. 2014). As travel is an inherently linear activity, and pedestrians and bicyclists are arguably much more sensitive to their environment, we need to look toward the kind of linear spatial units and finer-grained (parcel and point) measures presented in this paper.

The IAC method is important and relevant because despite the increasing volume of studies of bicycling and walking, measurement of environmental variables tends to operate at larger zonal scales originally designed to understand only motorized travel. Through the use of this new, linear spatial unit of analysis (the IAC), and by capitalizing on more detailed, higher-resolution data (parcel-level land-use classifications, network paths, parcel geometries, points where one can address a personal service utility like obtaining coffee, etc.), we can gain a deeper understanding of the built environment's influence on travel behavior and, perhaps more importantly, gain richer guidance on what we should do about it. This paper also introduces a refined set of built environment components (or dimensions) — urban aesthetics, land-use activity, and transport access — designed to both incorporate the prevailing D-variable construct while freeing us up to think beyond these zonal "dimensions." Finally, the methods presented in this paper open the door to future travel behavior research using more detailed geo-located point/ parcel data, such as business activity (number of employees, retail sales, tax revenue), criminal activity, and the location of pedestrian and bicycle collisions. In closing, improving our understanding of how to encourage human-scale travel (walking and bicycling) with human-scale measures is vitally important toward our achieving a broad array of public health, sustainability, and social benefits for all.

\section{References}

Appleyard, B. 2012. Sustainable and healthy travel choices and the built environment: Analyses of green and active access to rail transit stations along individual corridors. Transportation Research Record: Journal of the Transportation Research Board 2303 (-1): 38-45. doi:10.3141/2303-05.

Appleyard, B., C. E. Ferrell, M. A. Carroll, and M. Taecker. 2014. Toward Livability Ethics: A Framework to Guide Planning, Design and Engineering Decisions. http://trid.trb.org/view/2014/C/1289290.

Appleyard, B. S. 2011. New Methods to Measure Urban Environments for Consumer Behavior Research| Individual Access Corridor Analysis of Environmentally Sustainable Travel to Rapid Transit. University of California, Berkeley. http://gradworks.umi.com/34/44/3444652.html.

Badoe, D. A., and E. J. Miller. 2000. Transportation-land-use interaction: Empirical findings in North America, and their implications for modeling. Transportation Research Part D: Transport and Environment 5 (4): 235-63. doi:10.1016/S1361-9209(99)00036-X.

Ben-Akiva, M. E., and S. R. Lerman. 1985. Discrete Choice Analysis: Theory and Application to Travel Demand. MIT Press.

Bierlaire, M., and F. Crittin. 2003. Solving Large Scale Systems of Nonlinear Equations. http://infoscience. epfl.ch/record/77478.

Boarnet, M. G. 2011. A broader context for land use and travel behavior, and a research agenda. Journal 
of the American Planning Association 77(3): 197-213. doi:10.1080/01944363.2011.593483.

Boarnet, M. G., and S. Sarmiento. 1996. Can Land Use Policy Really Affect Travel Behavior? A Study of the Link Between Non-Work Travel and Land Use Characteristics. University of California Transportation Center. Working Paper qt95h07239. University of California Transportation Center. http://ideas.repec.org/p/cdl/uctcwp/qt95h07239.html.

Broach, J., J. Dill, and J. Gliebe. 2012. Where do cyclists ride? A route choice model developed with revealed preference GPS data. Transportation Research Part A: Policy and Practice 46(10): 1730-40. doi:10.1016/j.tra.2012.07.005.

Brownstone, D. 2008. Key Relationships between the Built Environment and VMT. Paper Prepared for the Committee on the Relationships Among Development Patterns, Vehicle Miles Traveled, and Energy Consumption. Transportation Research Board and the Division on Engineering and Physical Sciences.

Cao, X., P. L. Mokhtarian, and S. L. Handy. 2009. Examining the impacts of residential self-selection on travel behaviour: A focus on empirical findings. Transport Reviews 29(3): 359-95. doi:10.1080/01441640802539195.

Cervero, R., and K. Kockelman. 1997. Travel demand and the 3Ds: Density, diversity and design. Transportation Research Part D 2(3): 199-219.

Cervero, R., and M. Duncan. 2003. Walking, bicycling, and urban landscapes: Evidence from the San Francisco Bay Area. American Journal of Public Health 93(9): 1478-83.

Cervero, R., O. L. Sarmiento, E. Jacoby, L. F. Gomez, and A. Neiman. 2009. Influences of built environments on walking and cycling: Lessons from Bogotá. International Journal of Sustainable Transportation 3(4): 203-26. doi:10.1080/15568310802178314.

Clarke, K. A., and C. S. Signorino. 2010. Discriminating methods: Tests for non-nested discrete choice models. Political Studies 58(2): 368-88. doi:10.1111/j.1467-9248.2009.00813.x.

Crane, R. 2000. The influence of urban form on travel: An interpretive review. Journal of Planning Literature 15(1): 3-23. doi:10.1177/08854120022092890.

Crane, R., and R. Crepeau. 1998. Does neighborhood design influence travel?: A behavioral analysis of travel diary and GIS data. Transportation Research Part D: Transport and Environment 3(4): 225-38.

Dill, J. 2004. Measuring network connectivity for bicycling and walking. 83rd Annual Meeting of the Transportation Research Board, Washington, DC. http://reconnectingamerica.org/assets/Uploads/ TRB2004-001550.pdf.

Downs, A. 2005. Still Stuck in Traffic: Coping with Peak-Hour Traffic Congestion. Brookings Institution Press.

Ewing, R., and R. Cervero. 2010. Travel and the built environment. Journal of the American Planning Association 76(3): 265-94. doi:10.1080/01944361003766766.

Ewing, R., M. Greenwald, M. Zhang, J. Walters, M. Feldman, R. Cervero, L. Frank, and J. Thomas. 2011. Traffic generated by mixed-use developments—Six-region study using consistent built environmental measures. Journal of Urban Planning and Development 137(3): 248-61. doi:10.1061/ (ASCE)UP.1943-5444.0000068.

Ewing, R., and S. Handy. 2009. Measuring the unmeasurable: Urban design qualities related to walkability. Journal of Urban Design 14(1): 65-84. doi:10.1080/13574800802451155.

Handy, S. 2005. Transportation Research Board Special Report 282_Critical Assessment of the Literature on the Relationships Among Transportation, Land Use, and Physical Activity. Transportation Research Board. Retrieved from. http://trb.org/downloads/sr282papers/sr282Handy.pdf.

Hess, P. M., A. V. Moudon, and M. Logsdon. 2001. Measuring land use patterns for transportation research. Transportation Research Record: Journal of the Transportation Research Board 1780 (January): 17-24. doi:10.3141/1780-03. 
Lee, C., and A. V. Moudon. 2006. Correlates of walking for transportation or recreation purposes. Journal of Physical Activity \& Health 3: S77.

Lee, C., A.V. Moudon, and J. Y. P. Courbois. 2006. Built environment and behavior: Spatial sampling using parcel data. Annals of Epidemiology 16(5): 387-94. doi:10.1016/j.annepidem.2005.03.003.

Lee, J. 2013. USC School of Public Policy. Propensity to use public transportation: The role of perception and neighborhood type. Active Living Research. February, May. http://activelivingresearch.com/ node/ 12605 .

Moudon, A. V., and C. Lee. 2003. Walking and bicycling: An evaluation of environmental audit instruments. American Journal of Health Promotion 18 (1): 21-37.

Owens, P. M. 2008. Beyond Density: Measuring Neighborhood Form: Deriving Urban Form Measures for Neighborhoods, Blocks, and Streets in New England Towns. Saarbrücken, Germany: VDM Verlag Dr. Müller.

Pushkarev, B. S., J. M. Zupan, and Regional Plan Association (New York). 1977. Public Transportation and Land Use Policy. Bloomington: Indiana University Press.

Saelens, B. E., and S. L. Handy. 2008. Built environment correlates of walking: A review. Medicine and Science in Sports and Exercise 40 (7 Suppl): S550-S566. doi:10.1249/MSS.0b013e31817c67a4.

Salon, D., M. G. Boarnet, S. Handy, S. Spears, and G. Tal. 2012. How do local actions affect VMT? A critical review of the empirical evidence. Transportation Research Part D: Transport and Environment 17 (7): 495-508. doi:10.1016/j.trd.2012.05.006.

Smart Location Mapping | Smart Growth | US EPA. 2014. Accessed August 31. http://www.epa.gov/ smartgrowth/smartlocationdatabase.htm.

Train, K. 2009. Discrete Choice Methods with Simulation. New York: Cambridge University Press.

Walkscore.org. 2014. Accessed August 31. http://www.walkscore.com/.

Winters, M., K. Teschke, M. Grant, E. Setton, and M. Brauer. 2010. How far out of the way will we travel? Transportation Research Record: Journal of the Transportation Research Board 2190 (-1): 1-10. doi:10.3141/2190-01.

Zhang, L., J. H. Hong, A. Nasri, and Q. Shen. 2012. How built environment affects travel behavior: A comparative analysis of the connections between land use and vehicle miles traveled in US cities. Journal of Transport and Land Use 5(3). https://www.jtlu.org/index.php/jtlu/article/view/266.

Zhang, M., and N. Kukadia. 2005. Metrics of urban form and the modifiable areal unit problem. Transportation Research Record: Journal of the Transportation Research Board 1902(-1): 71-79. doi:10.3141/1902-09. 